\title{
Interviewing Older People in Residential Aged Care About Sexuality: Difficulties and Challenges
}

Laura Tarzia, ${ }^{1}$ Michael Bauer, ${ }^{1}$ Deirdre Fetherstonhaugh ${ }^{1}$, and Rhonda Nay ${ }^{2}$

Corresponding Author: Dr. Laura Tarzia

Email: 1.tarzia@1atrobe.edu.au

$\mathrm{Ph}:+61394795954$

${ }^{1}$ Australian Centre for Evidence Based Aged Care, La Trobe University, Victoria, Australia
${ }^{2}$ Australian Institute for Primary Care and Ageing, La Trobe University, Victoria, Australia

\section{Abstract}

Sexuality is a sensitive topic that can be awkward and difficult to research qualitatively. When the research participants are older people living in residential aged care, some of whom have dementia, the process can be even more challenging. In this article, we outline the difficulties encountered in conducting face-to-face qualitative interviews with older people in residential aged care as part of a research project on sexuality conducted in the states of Victoria and Queensland, Australia. We explore issues surrounding ethics and recruitment and considerations for accessing residents with cognitive impairment, difficulties with the interview process, and the collection of meaningful data from participants. We provide advice and recommendations for future researchers on how to potentially minimize problems associated with conducting qualitative face-to-face interviews on sexuality with older people in residential aged care.

\section{Keywords}

Face to face interviews; older people; dementia; sexuality; qualitative research; aged care; Australia

\section{Introduction}


Sexuality is not an easy subject on which to conduct qualitative research, particularly face-to-face interviews. In Western countries, despite the increasing 'sexualisation' of popular culture [1], there is still a certain degree of discomfort and embarrassment in talking about one's own sexuality [2-3]. For the older generation, who were in their teens and early twenties in the 1940s and 1950s, the topic of sex is likely to be even more taboo. Sex was rarely discussed during this period, and limited sex education was offered in schools [4].

Moreover, the media in Western societies generally portrays older people's sexuality as either non-existent, unacceptable, or the subject of humour [5], and this contributes to wider social myths and stereotypes about sex and older people. Even some health professionals have been found to hold negative attitudes towards older people's sexuality [6], and it is therefore unsurprising that this topic is a neglected area in social science and health research [7]. Taking these factors into account, it is understandable that some older people might feel uncomfortable speaking with anybody - let alone a complete stranger such as a researcher - about sex and intimacy.

When an older person lives in a residential aged care facility (RACF), this adds another level of complexity to the interview process. Older people in RACFs are considered vulnerable subjects, and permission is usually required from both the facility and the older person's proxy/guardian in order to contact them. Despite these hurdles, research has consistently shown that sexuality is an important aspect of later life [8,7], and that desire does not necessarily diminish upon admittance to a RACF [8]. Therefore, any methodological challenges to acquiring information from these populations must be identified and addressed.

In this article we explore some of the practical issues that can arise when conducting face-to-face qualitative interviews about sexuality with older people living in RACFs. Our aim is to assist other researchers who might wish to investigate this topic in the future by alerting them to potential problems and suggesting how they might be avoided. 


\section{About the Study}

This article stems from a larger body of work we conducted on the subject of sexuality in RACFs. Sexuality in our study was broadly defined, encompassing sexual intercourse, intimacy, closeness, companionship and love, as well as how one presents oneself as a man or a woman.

In Australia, RACFs provide "ongoing nursing and personal care to people who are no longer able to live independently or with the level of support available to them in the community" [Blinded for review]. Research consistently shows that the residential aged care environment is not conducive to the expression of sexuality amongst residents for a variety of reasons, including: negative staff and family attitudes [9-10], a building design and layout that impedes privacy [Blinded for review], and the fact that residents are often provided only with single beds and shared rooms [11]. Our study aimed to investigate the views of staff, family members, and residents, both with and without dementia, regarding the importance of sexuality and the barriers in the RACF environment.

During the course of the research, 16 face-to-face interviews were conducted with older people (nine men, seven women) living in RACFs in the states of Victoria and Queensland, Australia. Residents were aged between 57 and 101 years (average age 83) and five had a diagnosis of dementia or cognitive impairment. The research design was guided by naturalistic inquiry [12], with interviews being semi-structured and largely guided by the participants. Questions were open-ended in order to allow participants to provide meaningful answers. The overall findings of the study are reported elsewhere [Blinded for review].

\section{Qualitative Inquiry: Interviewing About Sex}


The methodological benefits and limitations of the qualitative face-to-face interview in a general context have been thoroughly discussed within the literature [13-15]. Benefits include the ability to record verbal data along with non-verbal information such as body language [16], as well as allowing the interviewer to "delve deeply into social and personal matters" [14, p315]. Critics, in contrast, have argued that face-to-face interviews are too subjective and can be unreliable [13]. Despite this, the interview has become well-established as an effective research methodology within the social and health sciences.

Many discussions of interview methodology have focused on the effectiveness of particular techniques in eliciting rich qualitative data from participants. The use of a semistructured conversational style rather than a formal set of interview questions, for example, has been suggested as a successful technique for discussing sensitive topics, as it allows for more flexibility [16]. The semi-structured interview allows the interviewer to probe participants on particular comments of interest rather than being forced to rigidly adhere to pre-determined questions, and, by the same token, can steer away from any line of questioning that appears to cause distress.

While there is not a large amount of existing literature focusing on face-to-face interviews with older people, a few authors have addressed this topic [17-19]. Robinson [18] has outlined the phases of qualitative face-to-face interviews with 'institutionalized' older people: introducing, personalizing, reminiscing, contextualizing, closing, and reciprocating [18]; he has suggested that these phases be followed to promote a successful interview. One study by Gledhill et al. [20] explored the sampling, ethical and methodological issues involved in recruiting older people for a project on sexuality. Their study differs from ours in that participants were community-dwelling, and therefore conventional recruitment strategies such as newspaper advertisements and word-of-mouth were able to be used. Furthermore, the study focused only on recruitment, and made no mention of the challenges involved in the 
interview process itself. The current paper therefore makes a unique contribution to the literature.

Although there is a small body of empirical work that has examined aspects of older people's sexuality in the RACF environment [21-22], our literature search did not yield enough material to carry out a systematic review to identify any methodological trends or common interview experiences.

\section{Recruitment}

Recruitment of participants is a major consideration for any research project about sexuality and older people, and can be one of the most significant impediments to progress. In most cases, the recruitment strategy must be approved by an ethics committee, and researchers should resign themselves to the fact that sexuality, dementia and frailty are words that almost always categorize a study as high-risk. Because of this, the details of the application are likely to be subjected to greater scrutiny than research involving other participants.

Although we used a multi-pronged approach to recruit residents for our project, including information flyers displayed at the RACF and presentations at RACF residentfamily and staff meetings, no residents expressed an interest in participating. The only effective recruitment strategy, in our experience, was having a reliable and enthusiastic 'insider' at a facility management level who was prepared to provide residents with information about the project, gauge their interest and, with their permission, give us their names. We then spoke to interested residents, provided the Participant Information and Consent Form and answered any questions they might have had. Once those residents who wanted to proceed had signed the consent form, we organized and conducted the interview. 
For residents with a diagnosis of dementia or cognitive impairment, assent was obtained from them at the time of the interview, in addition to written consent from their next of kin or authorized representative. Although family members often have an ambivalent attitude towards residents' sexuality [21], the fact that the preliminary information about the research came from the facility manager, rather than the researchers, may have provided endorsement and reassurance as to the legitimacy of the study. In fact, only one family member withdrew her consent for a resident with dementia, and this was due to a scheduling conflict, rather than concerns with the content of the research.

\section{Choice of Language}

In hindsight, advertising a research project as being about 'sexuality' might have discouraged or confused many potential participants. Outside of academia, 'sexuality' might not be a widely-understood term, and although our Participant Information and Consent Form did explain clearly that 'sexuality' meant a wide range of things, including grooming, dress, relationships, social interactions, and holding hands, many residents might have been concerned that we were going to ask them for intimate details of their sexual experiences. We suspect that the choice of language might have contributed to the difficulty finding residents willing to participate in the project, an experience shared by other researchers in the field [23].

Although wording is very important, ambiguity on consent forms or participant information sheets used in recruitment, or using a different verbal explanation than what is printed on the information sheets, is a risky strategy. It may mislead potential participants as to what the study is actually about, which is not only ethically questionable but possibly upsetting. One manager of a residential facility involved with our project chose to describe the study to an interested group of residents as being about 'relationships', as she thought that 
the word 'sexuality' might discourage them from participating. Although she managed to refer a number of residents to us for further information about the project, one gentleman was quite indignant when he eventually spoke to the interviewer. Upon hearing that he would be asked about 'sexuality', the resident responded, "I'm not speaking to you about that!" and refused to be interviewed. Another two residents changed their minds in the week between agreeing to be contacted and the interviewer actually arriving at their facility to discuss the project further.

During the interviews themselves, asking residents about 'sexuality' did not appear to cause offence, but residents were often vague or even dismissive in their responses, as shown in this exchange between one of the interviewers and a male resident:

Interviewer (I): Sexuality is about the sort of things that make us men and women. So, what comes to mind when I use the word sexuality. What do you think of? Resident (R): Something I don't think of actually.

I: What would you have thought about if I'd asked you that question maybe 20, 30 years ago?

R: I don't think it'd be any different.

In hindsight, we suggest that the participants were embarrassed by the use of the word 'sexuality' rather than offended, causing them to become taciturn and effectively shutting down the interview. As the authors [Blinded for review] have pointed out, the word 'sexuality' often conjures up “raunchy images of semi-naked young women on billboards and in the pages of magazines" [p192].

Another resident edged around the issue and referred to sex as "that" and it was not until one of the interviewers jokingly suggested the word, "hanky-panky", that the resident 
seemed to relax. The injection of humour and the use of non-serious terminology perhaps allowed the resident to think of the interview as more of a conversation with friends rather than a formal interview.

\section{Tangents and Avoidance}

Several participants seemed to go off on tangents during the course of the interviews. As Robertson and Hale [19] have pointed out, interviewing older people means being the recipient of many stories, some of which might not be relevant to the topic at hand. For some participants, however, tangents may have been a way of avoiding the topic of sexuality and returning to subject matter that was more comfortable to them. One couple who were interviewed together interrupted the flow of conversation about sexuality several times with random interjections such as:

Resident 1 (R1): We play bridge. Do you play bridge?

Interviewer (I): I don't, no.

Resident 2 (R2): What a shame.

Another resident, as we later discovered, deliberately avoided speaking with the interviewers about his relationship status. This resident, an 80-year-old man with dementia, adamantly stated throughout his interview that the relationship between himself and another woman within the facility was purely friendship. As he described it, "A friend, yes, that's all. A friend. No hanky-panky. Just a friend." Interestingly, when re-examining the data from the staff focus group at the same RACF, we found references to this resident and the relationship he was having with the woman in question: "You go down and there she is with her hand down his pants in the lounge room in front of everyone!" Clearly, the resident and the woman 
were more than friends, yet he did not want to divulge this, even when questioned directly. Given that the staff described the two residents as having the presence of mind to stop kissing and touching whenever a particular staff member - who routinely separated them approached, it is unlikely that the avoidance was caused by his dementia. It is possible that he was concerned about repercussions from staff if he spoke candidly with the interviewer, as it had been agreed upon during several family meetings that the relationship was not to continue.

\section{Avoiding Distress to Participants}

Considering the sensitive nature of sexuality as a topic, researchers need to be mentally prepared to deal with a range of emotional responses from interviewees. When interviewing older people, researchers should be mindful that the participant's point of reference about sexuality may often relate to a partner who has died. While this does not mean that the data they provide is less valuable, it might cause the interviewee to become emotional, which can be difficult for interviewers.

Several of our participants, when talking about partners who were deceased, expressed sadness over the loss of companionship and love. Older people might also mourn the loss of sex and intimacy itself, as a staff member at one facility recounted during a focus group session:

We have this resident that once said that he really misses making love. That's what he said, 'I really miss making love'. What do you say? 'I'm sorry.' But what do you say? And you feel for them, you know? (Staff focus group) 
Others were unhappy about other aspects of their lives such as the RACF environment or growing older. As one resident poignantly commented, "It's a miserable sort of life in lots of ways." Considering the risk of engaging with emotive issues, interviews should always be approached with sensitivity and tact, and the interviewer should be prepared to stop the interview altogether if necessary.

A degree of empathy is always required from an interviewer whenever an interviewee becomes emotional, but it is also important to investigate the individual's particular likes and dislikes. One of our interviewees, an 82-year-old woman with dementia, broke down in tears when asked a seemingly innocuous question about whether she would like to form a relationship within the facility. "I don't want to have a relationship with anybody in here," she cried. "They're all the same as me. They're not too well." Often with people with dementia, an effective response is to use touch to alleviate anxiety [24-25]. In this case, however, the interviewers present were both female, and staff had advised them not to touch the resident, as she did not like physical contact with other women. The interviewers were therefore forced to find another way to comfort her, which turned out to be diverting her attention and talking about her past pets, whose photos were hung all around the room.

\section{Speaking About Others Rather Than About Themselves}

Researchers should be aware that some older people might feel more comfortable speaking about others rather than about themselves, thereby distancing themselves from the discussion. Job et al. [17] in their article on interviewing "very old people", concurred with this assessment: "It was possible to spend three hours with [some participants] and learn a great deal about the people next door, without getting essential information about the respondents themselves" $[17, \mathrm{p} 8]$. This was certainly the case with some of the participants in our study, and it was very difficult to get them to speak at any length about their own 
sexuality or intimacy needs. The exception was one of the youngest participants, a 60-yearold man with early onset dementia who spoke openly about masturbation without any prompting from the interviewers. This openness may have been a result of the fact that he was of a different generation.

While it is not necessarily a problem if participants prefer to use examples involving others rather than themselves, it is important for researchers to consider this in wording their interview questions. In hindsight, our questions were probably too focused on the participants' experiences and feelings, which they might have been reluctant or embarrassed to share with us. Instead, we would suggest that researchers consider the use of scenarios about hypothetical older people to encourage interviewees to engage with the topic. This was a strategy that worked well in the interviews conducted with family members, as it allowed them to express their views without feeling obliged to reveal personal details directly. The use of scenarios is also common in other sensitive research areas, such as rape and sexual assault [26-27]. Describing a scenario to older people where fictional residents form a relationship with one another, or where a resident was prevented by staff from expressing some aspect of their sexuality, might have encouraged the interviewees to offer opinions. This might have subsequently led to them using personal experiences to illustrate a point if they felt they could relate to the material in some way.

\section{The Right Interviewer: Does it Make a Difference?}

If possible and practical, consider whether one particular interviewer might suit an interviewee more than another, or allow the participant themselves to choose. As Manderson et al. [28] pointed out in their analysis of the social dynamics of the interview, factors such as 
age, sex, and background "shape interview interactions and produce knowledge" [28, p1332]. When being interviewed about sexuality, older people might feel more comfortable speaking with someone of the same sex. Conversely, if they have had stronger relationships throughout their lives with the opposite sex, the reverse might be true.

It is also generally considered to be the case that interviewers closer to the age of the interviewee might be better at establishing a rapport, as their background, interests, and use of language may be similar [28-29]. Older people might also feel uncomfortable discussing intimate topics with a younger person. As Grenier [29] has pointed out, "while the location of researcher as granddaughter may facilitate trust, it may alter the content offered and how it is presented, with participants straying far from subjects not deemed appropriate to share with a granddaughter" [29, p720]. That said, it is not always the case that intergenerational interviews are unsuccessful. Job et al. [17] noted that the younger female researcher in their team was quite successful in establishing a rapport with the older interviewees, stating: "The old men tended to flirt with her; the old women tended to mother her; in either case, they were usually willing to tell her a lot about themselves" [17, p9]. It should also be noted that from a practical point of view, interviewers in their eighties are hard to come by, and even researchers in late middle age are still young enough to be the child of a person in this age group.

In our case, with two male and three female interviewers aged between 30 and 60 there seemed to be both positive and negative aspects of each interviewer-interviewee combination. For example, when a male resident was interviewed by a man and a woman, the resident completely ignored the woman interviewer and spoke only to the man. This led to the tone of the interview being one of male camaraderie. It is possible that the interviewee might have spoken more candidly had the woman left the room altogether. Conversely, another male resident, when interviewed by two women, adopted a somewhat flirty attitude 
and made comments such as, "Even though I'd like to have a relationship with you two girls, I don't know what to do with it!" It was unclear whether the resident was more or less inclined to reveal personal details to women as opposed to a man, although Job et al. [17] suggested that, "many men in our society. . . [relate] better to women in a situation involving confidences of a personal nature" [17, p9]. Echoing this sentiment, our oldest respondent, a 101-year-old man who was interviewed by a male researcher, commented that he preferred the company of women to men. Since his interview was somewhat uninformative, with most questions being answered with, "I don't know, really", this may suggest that he was not entirely comfortable with a male interviewer.

\section{Invisibility of Lesbian, Gay, Bisexual, Transgender, and Intersex Residents}

Despite repeated attempts to contact residents who identified as lesbian, gay, bisexual, transgender or intersex (LGBTI), we were unable to recruit any participants from these populations. According to a representative from a community health promotion organization we approached for assistance, there are several issues to consider that may have explained our inability to recruit LGBTI participants. These assertions are also supported by existing literature:

- LGBTI older people living in RACFs are 'deep in the closet'; fearful of discrimination if they disclose their sexual orientation. [30-32]

- RACFs are not aware of whether there are any LGBTI residents at their facility, and therefore cannot assist with recruitment. [33-34]

- The LGBTI community is ageist, and therefore it is difficult to access LGBTI older people through LGBTI media or community contacts [35-36]. 
Although we did contact an 'LGBTI-friendly' residential care facility, we were unable to negotiate any contact with their residents. We also contacted a gay men's health centre that provided residential services, as well as local community organizations for older gay men and lesbians, who informed us that we had very little chance of finding any older LGBTI people willing to participate. Unfortunately, we do not have any constructive suggestions for future researchers on this issue, other than recommending that all possible contacts and avenues of support be explored.

\section{What Have We Learned?}

Interviewing older people about sexuality in residential aged care can present some unique challenges. First, we recommend that researchers take care with the terminology used in all materials associated with advertising, recruitment and the interview itself. When recruiting, potential participants should not be inadvertently misled about the subject matter that will be discussed in the interview. However, during the interviews themselves it might be more productive to refer to 'relationships' or 'companionship' rather than 'sexuality' or 'intimacy'. Additionally, the use of scenarios detailing the experiences of hypothetical residents might encourage participants to speak more candidly than they would about themselves. This may reduce instances where the interviewee resorts to avoidance strategies such as tangents or distractions during the interview; this might also allay fears of negative repercussions.

Although it might not always be possible, we would recommend multiple meetings with residents, rather than a single interview. It is difficult to build rapport in a single interview, and an older person - or any person, for that matter - will be much more likely to feel relaxed when speaking about a sensitive subject like sexuality if they feel they have established some form of connection with the interviewer. An initial meeting where the 
interviewer 'gets to know' the older person, followed by a second visit for the interview where the subject of sexuality is discussed, might yield richer data. As DiCicco-Bloom and Crabtree [14] have outlined, interviewers should aim to progress past the 'apprehension' stage and into the 'exploration' or 'cooperation' phases, where participants feel comfortable sharing experiences that help the interviewer make sense of their world. This is unlikely to be achieved in a single session.

Additionally, speaking with a staff member and/or, in the situation of a person with dementia, the person who provides proxy consent beforehand, is highly recommended. Vital pieces of information concerning the participant (such as likes, dislikes, cultural or religious background) may be revealed. This is particularly important when interviewing people with dementia, where a seemingly innocuous comment can provoke an unpredictable reaction.

All interviewers should be prepared to experience some emotion from an older person if they are speaking about a loved one who has died, or if they are grieving the loss of sex and intimacy itself. Changing the topic of conversation, or bringing up a subject that may have more positive associations for the interviewee could be a good strategy for improving the older person's mood if they are becoming distressed. An additional benefit of speaking with families or staff beforehand is that any potential emotional triggers can be identified or avoided during the interview. Talking to family and staff may also result in suggestions for positive topics that could re-direct the older person if they become distressed. At all times, a sensitive and empathetic approach should be adopted. Researchers should not patronize the older person, and should be mindful of their ethical responsibility not to place participants at risk of emotional distress.

When interviewing people with dementia, it may be beneficial for interviewers to have some knowledge of, or experience with, this diagnosis. Even if consent is obtained from the person with dementia's proxy, and the person with dementia assents to the research, there 
is no guarantee that they will continue to consent throughout the interview process.

Therefore, it is important that interviewers are attuned to any behaviours that may indicate distress or discomfort such as "walking away. . . hand-wringing, crying" [37, p100].

Interviewers should also be prepared to accept that the person with dementia may have trouble recalling the purpose of the research and difficulty staying on topic, which might require extra reminding or prompting. Interview questions might need to be simplified or shortened to facilitate comprehension. If possible, the environment should be free from distractions, and interviews should take place at a time of day when the resident is willing and able to listen and process information [38], even if this means conducting the interview in multiple stages.

Finally, we encourage other researchers not to be dissuaded from conducting research on older people and sexuality. As Gott and Hinchcliff [7] have pointed out, "fear of causing offence should not be a barrier to conducting research on sexually related issues with older people" [7, p1626] . Despite the challenges this research presents, sexuality in older people living in RACFs is a topic that merits further attention.

\section{Acknowledgements}

Withheld for review

\section{References}

Author, (1999). Details withheld for peer review

Author and others, (2012). Details withheld for peer review.

Authors, (2012). Details withheld for peer review. 
1. Levy, A.: Female Chauvanist Pigs: Women and the Rise of Raunch Culture. Free Press, New York (2005)

2. Bell, J.: Why embarrassment inhibits the acquisition and use of condoms: A qualitative approach to understanding risky sexual behaviour. Journal of Adolescence 32, 379 391 (2009). doi:10.1016/j.adolescence.2008.01.002

3. Dyer, K., das Nair, R.: Why Don't Healthcare Professionals Talk About Sex? A Systematic Review of Recent Qualitative Studies Conducted in the United Kingdom. Journal of Sexual Medicine (2012). doi:DOI: 10.1111/j.1743-6109.2012.02856.x

4. Davis, A.: 'Oh no, nothing, we didn't learn anything': sex education and the preparation of girls for motherhood, c.1930-1970. History of Education 37(5), 661-677 (2008). doi:10.1080/00467600701727730

5. Benbow, S.M., Beeston, D.: Sexuality, aging, and dementia. Int. Psychogeriatr. 24(7), 1026-1033 (2012).

6. Gott, M., Galena, E., Hinchliff, S., Elford, H.: "Opening a can of worms": GP and practice nurse barriers to talking about sexual health in primary care. Fam. Pract. 21(5), 528$536(2004)$.

7. Gott, M., Hinchliff, S.: How important is sex in later life? The views of older people. Soc. Sci. Med. 56(8), 1617-1628 (2003).

8. Elias, J., Ryan, A.: A review and commentary on the factors that influence expressions of sexuality by older people in care homes. J. Clin. Nurs. 20, 1668-1676 (2011).

9. Hajjar, R., Kamel, H.: Sexuality in the nursing home, part 1: Attitudes and barriers to sexual expression. Journal of the American Medical Directors Association 4(3), 152156 (2003). doi:10.1097/01.JAM.0000061465.00838.57 
10. Lindsay, J.R.: The Need for More Specific Legislation in Sexual Consent Capacity Assessments for Nursing Home Residents: How Grandpa Got His Groove Back. Journal of Legal Medicine 31, 303-323 (2010). doi:10.1080/01947648.2010.505835

11. Lemieux, L., Kaiser, S., Pereira, J., Meadows, L.M.: Sexuality in palliative care: patient perspectives. Palliative Medicine 18, 630-637 (2004). doi:10.1191/0269216304pm941oa

12. Lincoln, Y.S., Guba, E.G.: Naturalistic Inquiry. Sage Publications, London (1985)

13. Kvale, S.: Ten standard Objections to Qualitative Research Interviews. Journal of Phenomenological Psychology 25(2), 147-173 (1994). doi:10.1163/156916294X00016

14. DiCicco-Bloom, B., Crabtree, B.F.: The qualitative research interview. Medical Education 40, 314-321 (2006). doi:10.1111/j.1365-2929.2006.02418.x

15. King, N., Horrocks, C.: Interviews in qualitative research. Sage, London (2010)

16. Barriball, K.L., While, A.: Collecting data using a semi-structured interview: a discussion paper. Journal of Advanced Nursing 19, 328-335 (1994). doi:10.1111/j.13652648.1994.tb01088.x

17. Job, E., Johansen, C., Jones, J., Spenceley, E.: Interviewing Very Old People. Australasian Journal on Ageing 1(2), 7-11 (1982). doi:10.1111/j.17416612.1982.tb00983.x

18. Robinson, J.P.: Phases of the Qualitative Research Interview with Institutionalized Elderly Individuals. Journal of Gerontological Nursing 26(11), 17-23 (2000). 19. Robertson, L., Hale, B.: Interviewing Older People; Relationships in Qualitative Research. The Internet Journal of Allied Health Sciences and Practice 9(3) (2011). 
20. Gledhill, S.E., Abbey, J.A., Schweitzer, R.: Sampling methods: methodological issues involved in the recruitment of older people into a study of sexuality. The Australian Journal of Advanced Nursing 26(1), 84-94 (2008).

21. Frankowski, A.C., Clark, L.J.: Sexuality and Intimacy in Assisted Living: Residents' Perspectives and Experiences. Sexuality Research \& Social Policy 6(4), 25-37 (2009). doi:10.1525/srsp.2009.6.4.25

22. Aizenberg, D., Weizman, A., Barak, Y.: Attitudes Toward Sexuality Among Nursing Home Residents. Sexuality and Disability 20(3), 185-189 (2002). doi:10.1023/A:1021445832294

23. Malta, S.: Love Actually! Older Adults and their Romantic Internet Relationships. Australian Journal of Emerging Technologies and Society 5(2), 84-102 (2007).

24. Connor, A., Howett, M.: A Conceptual Model of Intentional Comfort Touch. Journal of Holistic Nursing 27(2), 127-135 (2009).

25. Kim, E.J., Buschmann, M.T.: The effect of expressive physical touch on patients iwht dementia. International Journal of Nursing Studies 36, 235-243 (1999).

26. Abrams, D., Viki, G.T., Masser, B.: Perceptions of Stranger and Acquaintance Rape: The Role of Benevolent and Hostile Sexism in Victim Blame and Rape Proclivity. Journal of Personality and Social Psychology 84(1), 111-125 (2003). doi:10.1037/00223514.84.1.111

27. Masser, B., Lee, K., McKimmie, B.M.: Bad Woman, Bad Victim? Disentangling the Effects of Victim Stereotypicality, Gender Stereotypicality and Benevolent Sexism on Acquaintance Rape Victim Blame. Sex Roles 72, 494-504 (2010). doi:10.1007/s11199-009-9648-y 
28. Manderson, L., Bennett, E., Andajani-Sutjahjo, S.: The Social Dynamics of the Interview: Age, Class, and Gender. Qualitative Health Research 16(10), 1317-1334 (2006). doi:10.1177/1049732306294512

29. Grenier, A.M.: Crossing Age and Generational Boundaries: Exploring Intergenerational Research Encounters. Journal of Social Issues 63(4), 713-727 (2007). doi:10.1111/j.1540-4560.2007.00532.x

30. Chandler, M., Panich, E., South, C., Margery, M., Maynard, N., M, N.: The lion, the witch and the wardrobe; Ageing GLBTIs (gay, lesbian, bisexual, transgender, and intersex people) and aged care: a literature review in the Australian context. Geriaction 23(4), 15-21 (2005).

31. Barrett, C., Harrison, J., Kent, J.: Permission to speak. In. Matrix Guild Victoria Inc, Melbourne, (2009)

32. Stein, G.L., Beckermam, N.L., Sherman, P.A.: Lesbian and Gay Elders and Long-Term Care: Identifying the Unique Psychosocial Perspectives and Challenges. Journal of Gerontological Social Work 53, 421-435 (2010).

33. Harrison, J.: It's none of my business': Gay and lesbian invisibility in aged care. Australian Occupational Therapy Journal 48(3), 142-145 (2001).

34. GLBTI Retirement Association Inc., Curtin Health Innovation Research Institute: We Don't Have Any of Those People Here: Retirement accommodation and aged care issues for non-heterosexual populations. In. Perth, WA, (2010)

35. Butler, S.S.: Gay, Lesbian, Bisexual, and Transgender (GLBTI) Elders. Journal of Human Behavior in the Social Environment 9(4), 25-44 (2004).

36. Slevin, K., CE, M.: Aging and Ageism among Old Lesbians and Gay Men. In: Carpenter, L.M., DeLamater, J. (eds.) Sex for Life: From Virginity to Viagra, How Sexuality Changes Throughout Our Lives. New York University Press, New York (2012) 
37. Beattie, E.: Research Participation of Individuals with Dementia: Decisional Capacity, Informed Consent, and Considerations for Nurse Investigators. Research in Gerontological Nursing 2(2), 94-102 (2009). doi:10.3928/19404921-20090401-01 38. Mayo, A.M.: Considerations of Informed Consent and Decision-Making Competence in Older Adults with Cognitive Impairment. Research in Gerontological Nursing 2(2), 102-111 (2009). doi:10.3928/19404921-20090401-08 